\title{
CHARACTERIZATION OF INSECTICIDAL PEPTIDES FROM VENOM OF AUSTRALIAN FUNNEL-WEB SPIDERS
}

\author{
VONARX E. J. (1), TYLER M. I. (2), ATKINSON R. K. (3), HOWDEN M. E. H. (1)
}

(1) School of Biological and Chemical Sciences, Deakin University, Geelong, Victoria, Australia; (2) Australian Proteome Analysis Facility, Macquarie University, Sydney, New South Wales, Australia; (3) School of Applied Science, University of Southern Queensland, Toowoomba, Queensland, Australia.

\begin{abstract}
Australian funnel-web spiders are relatively large primitive hunting spiders. Male Atrax robustus spiders have been responsible for a number of human deaths. Venom was collected from the species Hadronyche infensa (Hickman) [female], $H$. formidabilis [male and female], $H$. versuta [female], and $A$. robustus (Cambridge) [male] and was fractionated by high performance liquid chromatography. This resulted in the isolation and purification of a homologous series of 7 insecticidal peptides of relatively low molecular mass (approximately $4 \mathrm{kDa}$ ). The amino acid sequences of these toxins consisted of 36 or 37 amino acids and were named atracotoxins. For the major bioassay of these toxins, we used the cotton bollworm, Helicoverpa armigera (Hubner), due to the great damage it causes to crops worldwide. These toxins, when injected subcutaneously into fifth or sixth instar larvae of Helicoverpa armigera, were lethal or caused an apparently irreversible writhing. The toxin from $H$. versuta venom showed no significant toxicity when subcutaneously injected into newborn mice. One of the toxins was found to have a free acid carboxyl terminus. These toxins have great potential as lead compounds for insecticide design or for incorporation in recombinant baculovirus insecticides.
\end{abstract}

KEY WORDS: Australian funnel-web spiders, Hadronyche and Atrax species, venom, insecticidal toxins, peptides, Helicoverpa armigera.

\section{CORRESPONDENCE TO:}

MERLIN HOWDEN, 297 Halcrows Road, Glenorie, 2157, Sydney, New South Wales, Australia. Phone: + 6129652 1238. Fax: + 6129652 0046. Email: m.howden@unsw.edu.au. 


\section{INTRODUCTION}

Venoms are increasingly being seen as a source of novel biological agents in fields as diverse as medicine and agriculture. Numerous spider venoms have been examined for activity in insects. Their biologically active components are usually polyamines and peptides $(5,11,15,20)$. In general, polyamine toxins cause fasteracting, reversible incapacitation of the target insect, whereas peptide toxins are associated with longer-term effects. Other venoms such as those from scorpions and ants are rich sources of insect-active peptides $(4,16,23,24)$.

We have sought new compounds that could specifically provide a basis for the development of agricultural insecticides, either through direct application or via recombinant vectors. We have shown that venoms of Australian funnel-web spiders show insecticidal activity (2). Here, we report the biochemical examination of these venoms, revealing discrete active components which were purified and characterized as peptides toxic to insects.

The existence of these toxins, which are relatively small and highly effective, encourages further research into field delivery systems either as lead structures for insecticide design or incorporated in recombinant baculovirus insecticides (9). Comparison with the mammalian toxin present in the same venom indicated lack of mammalian toxicity in one of these insecticidal peptides (3). This work preceded and was the genesis of that of King et al. (12).

\section{MATERIALS AND METHODS}

The species Hadronyche infensa (Hickman), H. formidabilis, H. versuta (Rainbow), and Atrax robustus (Cambridge) were field-collected. Their identity was confirmed by the Australian Museum when necessary. Venom was collected by direct aspiration from the live spiders' fangs into silanized (Coatasil, Ajax Chemicals, Australia) glass pipettes, and stored frozen at $-20^{\circ} \mathrm{C}$ until required. It was retrieved from the pipettes by repeated washing with $0.1 \% \mathrm{v} / \mathrm{v}$ aqueous trifluoroacetic acid (TFA), and then freeze-dried. Acetonitrile for high performance liquid chromatography (HPLC) was purchased from Mallinckrodt, Australia; TFA and heptafluorobutyric acid (HFBA) from Pierce Chemical Company; dithiothreitol and 4-vinylpyridine from Sigma Chemical Company; and endopeptidase Glu-C from ICN Immunobiologicals, Costa Mesa, California. lodoacetic acid was supplied by Merck Chemical Company. All HPLC 
water used was produced by a Liquipure Modulab Water System and vacuum filtered through a $0.45-\mu \mathrm{m}$ nylon membrane.

\section{Culturing of Helicoverpa armigera}

Larvae of the cotton bollworm, Helicoverpa armigera, were used for the bioassay of spider venoms and their fractions. The larvae were kept in an air-conditioned laboratory and were cultured essentially by the same methods as previously described for Helicoverpa punctigera (2).

\section{Bioassay of venoms and fractions}

Subcutaneous injections were administered under the lateral cuticle of fifth or sixth instar larvae of Helicoverpa armigera, as previously described (2). An oral ingestion activity test was also undertaken using crude $H$. infensa venom. Crude venom was mixed with a small amount of synthetic diet and was fed to 10 third instar larvae of Helicoverpa armigera.

\section{Venom fractionation}

Freeze-dried venom was reconstituted in $0.1 \%$ aqueous TFA to various known concentrations from $10-50 \mathrm{mg} / \mathrm{ml}$. These solutions were fractionated on a Pharmacia LKB HPLC system utilizing an LKB 2240 Rapid Spectral Detector in conjunction with LKB "Wavescan" data manipulation software. A Waters Deltapak C18 $(3.9 \mathrm{~mm} \times 150 \mathrm{~mm}, 10 \mu \mathrm{m} \times 300 \mathrm{~A})$ and a Waters Deltapak C4 $(7.8 \mathrm{~mm} \times 300 \mathrm{~mm}$, $15 \mu \mathrm{mX} 300 \mathrm{~A})$ were the HPLC columns used. HPLC elution gradients were composed of an increasing acetonitrile percentage ( $0 \%-60 \%)$ in constant $0.1 \% \mathrm{v} / \mathrm{v}$ TFA solution. Materials corresponding to UV absorbance peaks were manually collected in polypropylene containers and lyophilized.

Further fractionation was necessary only for the purification of the toxins Ar1, Hf1a and $\mathrm{H} f \mathrm{~b}$. For these, an increasing acetonitrile concentration and either constant $0.05 \%$ HFBA or $0.01 \mathrm{M}$ ammonium acetate solution ( $\mathrm{pH} 5.8$ ) were used, respectively. Fractions were selected for sequencing according to positive bioassay results. Purity was confirmed during amino acid sequencing, in which no fraction revealed more than one sequence. Toxin yields were estimated indirectly from sequencing yields using B-lactoglobulin as sequencing standard. Subsequently, they were calculated by 
comparing UV absorbances at $210 \mathrm{~nm}$ based on the Hv1 toxin ratio of 0.02 absorbance units/ug dry weight.

\section{Characterization of toxins}

Peptide amino acid sequencing was carried out with a gas-phase sequencer (Applied Biosystems, model 470A) using the manufacturer's programs with slight modification. Phenylthiohydantoin-amino acids were identified by an on-line Applied Biosystems, model $120 \mathrm{~A}$, analyser. Typically, from $500 \mathrm{pmol}$ to $1 \mathrm{nmol}$ of toxin was loaded onto the sequencer support for each run. Cysteine residues were identified by subsequent sequencing of peptides reduced by dithiothreitol and alkylated by iodoacetic acid or 4-vinylpyridine.

Amino acid analysis of toxins was performed with a Waters PicoTag workstation, using either a Waters or Applied Biosystems HPLC system to quantify the phenylthiocarbamoyl amino acids. Gas-phase hydrolysis of peptides was achieved with constant boiling hydrochloric acid containing $0.1 \%$ phenol at $150^{\circ} \mathrm{C}$ for one hour. Purified peptides were alkylated and reduced with dithiothreitol in a standard TRIS reduction buffer at $\mathrm{pH}$ 8.2. Cysteine residues were then labelled with either iodoacetic acid or 4-vinylpyridine. The reduction mixture was injected into the HPLC apparatus in order to isolate the pure reduced and alkylated peptide.

All time-of-flight mass spectral analyses were made with a Biolon Biopolymer Mass Analyser (Applied Biosystems). An accelerating voltage of 15,000 volts and a collection time of about 2,000 seconds $\left(3 \times 10^{6}\right.$ start pulses) were used.

\section{Enzymatic digestion}

The reduced and alkylated peptides were cleaved with endopeptidase Glu-C in an ammonium hydrogen carbonate buffer, $\mathrm{pH} 7.8$, essentially by the method of Houmard et al. (10), under conditions designed to restrict the cleavage to glutamic acid residues only. Digests were fractionated by HPLC and manually collected for further analysis.

\section{Characterization of the carboxyl terminus of toxin Hi1b}

In order to identify the C-terminus of native toxin Hi1b, a comparative approach was adopted based on the synthesis by standard Fmoc chemistry of both the acid and the amide forms of a fragment bearing the C-terminus of the native peptide. Such a 
fragment was produced by cleavage of the toxin with endoproteinase Glu-C. The resulting deprotected synthetic peptides were then alkylated with iodoacetic acid in a fashion similar to that used for the native toxins. In this way, peptides corresponding to the amino acid residues 29-37 of native Hi1b were synthesized in both amide and acid forms, as shown below:

$\mathrm{Hi} 1 \mathrm{~b}-\mathrm{COOH} \quad \mathrm{H}_{2} \mathrm{~N}-\mathrm{N}$ G N Q V K R C D-COOH

$\mathrm{Hi} 1 \mathrm{~b}-\mathrm{CONH}_{2} \quad \mathrm{H}_{2} \mathrm{~N}-\mathrm{N}$ G N Q V K R C D-CONH $\mathrm{C}_{2}$

Hi1b-native $\quad \mathrm{H}_{2} \mathrm{~N}-\mathrm{N}$ GN Q V K RC D-?

The HPLC elution characteristics of these three peptides were then compared using both a reversed phase column (Waters Deltapak, 3.9mmX150mmX5 $\mu \mathrm{m}$ ) and a cation exchange column (Polycat A, 4.6mmX250mmX5 $\mu \mathrm{m}$, PolyLC, Activon, Melbourne).

\section{Estimation of the effective toxic dose $\left(E D_{50}\right)$ of toxin $\mathrm{Hv} \mathbf{1}$}

Sixth instar Helicoverpa armigera larvae (10 for each dose level) were individually injected under the lateral cuticle with doses of toxin Hv1 (as listed in Table 4) in $5 \mu \mathrm{l}$ of $0.75 \% \mathrm{v} / \mathrm{v}$ sodium chloride solution. The number of dead or writhing larvae (9) after $24 \mathrm{~h}$ was recorded. The death or writhing percentage was the criterion used rather than the death percentage, since the latter was found to be too variable. Thus, the $E D_{50}$, instead of the $L D_{50}$, was measured. Probit estimation of the $E D_{50}$ values for Helicoverpa armigera was based on the method of Finney (7).

\section{Effect of toxin Hv1 in newborn mice}

Newborn mice were less than $24 \mathrm{~h}$ old. A total of 8 newborn Swiss Outbred mice were weighed. The average mass per mouse observed was $1.75 \mathrm{~g}$. Mice were divided into a control group and a test group, each group consisting of 4 individuals. The bioassay procedure was based on that of Brown et al. (3) and Sutherland (22). Each mouse in the test group received a single dose of a solution containing $4.4 \mu \mathrm{g} \mathrm{Hv} 1$ $(2.5 \mathrm{mg} / \mathrm{kg}$ body mass) by subcutaneous injection into the dorsum using a microliter syringe (Scientific Glass Engineering). This dose was set at 5 times the $L_{50}$ for the mammalian toxin versutoxin (3) present in the same venom, and measured under similar conditions in newborn mice. Each mouse of the control group received a 
similar injection of solvent only. Mice were observed hourly for the first $6 \mathrm{~h}$, and then at $24 \mathrm{~h}$.

\section{RESULTS}

Hadronyche infensa specimens produced an average venom yield of approximately $0.8 \mathrm{mg}$ dry mass per "milking". Female $H$. versuta spiders provided from 0.55 to $1.4 \mathrm{mg}$ dry mass/"milking". Male $A$. robustus spiders were the least productive. They afforded only approximately $0.02 \mathrm{mg}$ of dried venom per "milking". Male and female $H$. formidabilis spiders produced the largest venom yield, an average of $1.2 \mathrm{mg}$ dry mass/"milking". Toxin yields per mg dry mass of venom were estimated and are presented in Table 1.

\section{Isolation of toxins}

Figure 1 shows the HPLC profile of crude venom from female $H$. infensa spiders. Bioassays indicated that peaks marked $A, B$ and $C$ displayed toxicity towards Helicoverpa armigera larvae (Table 1). The resulting toxins were named atracotoxinHi1a, b and c, respectively, according to the nomenclature of King, Tedford and Maggio (12). Their names were abbreviated as ACTX-Hi1a, b and c, correspondingly. Venom from both female $H$. versuta and male $A$. robustus showed an active component at elution times comparable to those of the toxins in $\mathrm{H}$. infensa venom when subjected to a similar fractionation/bioassay procedure. These toxins were named atracotoxin-Hv1 and -Ar1, respectively.

Venom from female $H$. formidabilis spiders after all processing afforded two active toxins named atracotoxin- $\mathrm{H} f \mathrm{a}$ and $\mathrm{b}$. The toxins yields were 8.8 and $4.2 \mu \mathrm{g} / \mathrm{mg}$ of dried crude venom, respectively. Venom from male spiders was not available for fractionation. Figure 2 shows a representative HPLC profile of crude venom from $\mathrm{H}$. formidabilis in constant $0.1 \%$ TFA. The peak marked A had HPLC elution characteristics similar to those of peaks displayed by the venoms of other funnel-web spider species and which corresponded to material showing insecticidal activity. This material was a mixture. Its further fractionation gave the HPLC profile shown in Figure 3. This Figure clearly shows the presence of two major components. These were named atracotoxin-Hf1a and b. 
All fractions derived from this venom sample (2mg dry mass) were examined by the bioassay procedure described above. Results indicated that only the fractions containing the two toxins named above were active.

\section{Characterization of toxins}

Gas-phase amino acid sequencing of all isolated toxins gave the sequences shown in Figure 4. Fractionation of endopeptidase Glu-C digests of these toxins resulted in carboxyl terminus peptides of nine or ten amino acids, which were again subjected to gas-phase sequencing (see the residues underlined in Figure 4). Results confirmed the sequences for the toxins. Amino acid analyses of the toxins and of endopeptidase Glu-C fragments are shown in Tables 2.1, 2.2 and 2.3. They are also in agreement with the sequencing results. Final confirmation of these primary structures was provided by time-of-flight plasma desorption mass spectrometry, in which ions correlating with the calculated masses of most of the toxins and endopeptidase Glu-C fragments were found (Tables 3.1 and 3.2).

\section{Characterization of the carboxyl terminus of atracotoxin-Hi1b}

We compared the elution characteristics in reversed phase (Figure 5) and cation exchange (not presented) HPLC of the peptides produced by endopeptidase Glu-C cleavage of atracotoxin-Hi1b and of its synthetic acid and amide analogues. The peptide from the native toxin co-eluted with the synthetic peptide in its acid form. It was concluded that the native atracotoxin-Hi1b has a free acid moiety at the carboxyl terminus.

\section{Effective toxic dose $\left(\mathrm{ED}_{50}\right)$ of atracotoxin-Hv1}

The number of dead or writhing Helicoverpa armigera larvae (expressed as a percentage of the number in a test group) after 24h was recorded against the toxin dose in $\mu \mathrm{g}$ (Table 4). The $\mathrm{ED}_{50}$ was $7 \mu \mathrm{g} / \mathrm{larva}$. The mean larval mass, measured in 20 sixth instar larvae, was $502 \mathrm{mg}$. The range of masses was $389-607 \mathrm{mg}$. The $\mathrm{ED}_{50}$ for atracotoxin-Hv1 can therefore be expressed as $14 \mu \mathrm{g} / \mathrm{g}$ of larva. 


\section{Effect of atracotoxin-Hv1 on newborn mice}

All mice in both test and control groups survived without apparent toxic effect_beyond $24 \mathrm{~h}$ post injection. This indicated a lack of mammalian toxicity for atracotoxin-Hv1 at the dose employed.

\section{Oral ingestion activity test of crude $H$. infensa venom}

No effect was observed in this test, even though approximately 4 times the dose required for lethality by injection was orally consumed by the larvae.

Table 1: Toxin yields and bioassay results.

\begin{tabular}{|c|c|c|c|c|c|c|}
\hline \multirow[t]{2}{*}{ Atracotoxin } & \multirow{2}{*}{$\begin{array}{l}{ }^{a} \text { Yield/mg } \\
\text { dry } \\
\text { venom } \\
\text { (pmol) }\end{array}$} & \multicolumn{3}{|c|}{${ }^{b}$ Affected larvae } & \multicolumn{2}{|c|}{$\begin{array}{l}{ }^{c} \text { Estimated } \\
\text { dose/larvae }\end{array}$} \\
\hline & & $24 \mathrm{~h}$ & $48 \mathrm{~h}$ & $72 h$ & (pmol) & $(\mu \mathrm{g})$ \\
\hline${ }^{*}-\mathrm{Hi} 1 \mathrm{a}$ & 1256 & $4 / 8$ & $7 / 8$ & $7 / 8$ & 942 & 4 \\
\hline${ }^{*}-\mathrm{Hi} 1 \mathrm{~b}$ & 1056 & $7 / 8$ & $8 / 8$ & $8 / 8$ & 792 & 3 \\
\hline${ }^{*}-\mathrm{Hi} 1 \mathrm{c}$ & 700 & $3 / 8$ & $6 / 8$ & $6 / 8$ & 525 & 2 \\
\hline${ }^{\dagger}-\mathrm{Hv} 1$ & 1228 & $4 / 8$ & $7 / 8$ & $7 / 8$ & 767 & 3 \\
\hline${ }^{\ddagger_{-} \text {Ar1 }}$ & 165 & $3 / 7$ & $6 / 7$ & $6 / 7$ & 94 & 0.3 \\
\hline$\S_{-H f 1 a}$ & 2200 & $4 / 7$ & $5 / 7$ & $5 / 7$ & & \\
\hline$\S_{-H f 1 b}$ & 1050 & $3 / 7$ & $6 / 7$ & $6 / 7$ & & \\
\hline
\end{tabular}

*From $H$. infensa (female).

${ }^{\dagger}$ From H. versuta (female).

${ }^{\ddagger}$ From Atrax robustus (male).

$\S$ From $H$. formidabilis.

${ }^{a}$ Yields and doses estimated indirectly from amino acid analysis, gas-phase sequencing or absorbance at $210 \mathrm{~nm}$.

${ }^{b}$ As defined in the 'bioassay of venoms and fractions' section of Materials and Methods.

${ }^{c}$ The actually injected dose. 
Table 2.1: Amino acid composition of the toxins.

\begin{tabular}{l|c|c|c|c|c|c|c|c}
\hline \multicolumn{9}{c}{ Complete atracotoxins ACTX- } \\
\hline Amino acid & \multicolumn{2}{|c}{ Hi1a } & \multicolumn{2}{c}{ Hi1b } & \multicolumn{2}{c}{ Hi1c } & \multicolumn{2}{c}{ Ar1 } \\
\hline & cal. & seq. & cal. & seq. & cal. & seq. & cal. & seq. \\
\hline D & 4.9 & 5 & 5.7 & 6 & 5.3 & 6 & 5.3 & 5 \\
\hline E & 4.1 & 4 & 5.1 & 5 & 3.9 & 4 & 5.4 & 5 \\
\hline S & 3.4 & 4 & 2.8 & 3 & 4.1 & 4 & 4.6 & 5 \\
\hline T & 3.6 & 4 & 2.7 & 3 & 2.7 & 3 & 2.3 & 2 \\
\hline G & 2.2 & 2 & 2.4 & 2 & 2.3 & 2 & 3.0 & 3 \\
\hline H & 0.9 & 1 & 0.0 & 0 & 0.0 & 0 & 1.1 & 1 \\
\hline A & 1.2 & 1 & 1.1 & 1 & 1.2 & 1 & 0.0 & 0 \\
\hline Y & 2.0 & 2 & 2.0 & 2 & 1.8 & 2 & 1.7 & 2 \\
\hline R & 1.3 & 1 & 1.3 & 1 & 2.2 & 2 & 1.4 & 1 \\
\hline P & 3.2 & 3 & 3.9 & 4 & 2.4 & 2 & 2.6 & 3 \\
\hline V & 1.1 & 1 & 1.1 & 1 & 1.1 & 1 & 1.8 & 2 \\
\hline F & 0.0 & 0 & 0.0 & 0 & 0.0 & 0 & 0.0 & 0 \\
\hline I & 0.0 & 0 & 0.9 & 1 & 0.8 & 1 & 0.9 & 1 \\
\hline K & 2.0 & 2 & 2.0 & 2 & 2.2 & 2 & 1.0 & 1 \\
\hline C & $*$ & 6 & $*$ & 6 & $*$ & 6 & $*$ & 6 \\
\hline
\end{tabular}

cal.: Ratio calculated from amino acid analysis.

seq.: Ratio expected from the sequence.

${ }^{*}$ Not determined. 
Table 2.2: Amino acid composition of the toxins.

\section{Complete atracotoxins ACTX-}

\begin{tabular}{l|c|c|c|c|c|c}
\hline Amino acid & \multicolumn{2}{|c|}{ Hv1 } & \multicolumn{2}{c|}{ Hf1a } & \multicolumn{2}{c}{ Hf1b } \\
\hline & cal. & seq. & cal. & seq. & cal. & seq. \\
\hline $\mathrm{D}$ & 5.7 & 6 & 3.9 & 4 & 6.4 & 6 \\
\hline $\mathrm{E}$ & 5.2 & 5 & 1.1 & 1 & 4.2 & 4 \\
\hline $\mathrm{S}$ & 4.0 & 4 & 2.9 & 3 & 4.1 & 4 \\
\hline $\mathrm{T}$ & 2.8 & 3 & 3.0 & 3 & 4.0 & 4 \\
\hline $\mathrm{G}$ & 3.0 & 2 & 4.0 & 4 & 2.3 & 2 \\
\hline $\mathrm{H}$ & 0.0 & 0 & 0.0 & 0 & 0.0 & 0 \\
\hline $\mathrm{A}$ & 0.0 & 0 & 3.0 & 3 & 0.0 & 0 \\
\hline $\mathrm{Y}$ & 0.8 & 1 & 1.0 & 1 & 1.1 & 1 \\
\hline $\mathrm{R}$ & 1.6 & 1 & 1.9 & 2 & 1.9 & 2 \\
\hline $\mathrm{P}$ & 3.8 & 4 & 5.8 & 6 & 3.3 & 3 \\
\hline $\mathrm{V}$ & 1.0 & 1 & 1.0 & 1 & 1.0 & 1 \\
\hline $\mathrm{F}$ & 1.0 & 1 & 0.0 & 0 & 1.0 & 1 \\
\hline $\mathrm{I}$ & 1.0 & 1 & 0.0 & 0 & 0.9 & 1 \\
\hline $\mathrm{K}$ & 2.2 & 2 & 1.0 & 1 & 1.9 & 2 \\
\hline $\mathrm{C}$ & $*$ & 6 & $*$ & 8 & $*$ & 6 \\
\hline
\end{tabular}

cal.: Ratio calculated from amino acid analysis.

seq.: Ratio expected from the sequence.

${ }^{*}$ Not determined.

Table 2.3: Amino acid composition of the toxins.

Endopeptidase Glu-C digest, carboxyl terminus fragments from ACTX-

\begin{tabular}{l|c|c|c|c|c|c}
\hline Amino acid & \multicolumn{2}{|c|}{ Hi1a } & \multicolumn{2}{c|}{ Hi1b } & \multicolumn{2}{c}{ Hi1c } \\
\hline & cal. & seq. & cal. & seq. & cal. & seq. \\
\hline $\mathrm{D}$ & 3.2 & 3 & 2.4 & 3 & 3.1 & 3 \\
\hline $\mathrm{E}$ & 1.1 & 1 & 1.3 & 1 & 1.1 & 1 \\
\hline $\mathrm{G}$ & 1.0 & 1 & 1.5 & 1 & 1.1 & 1 \\
\hline $\mathrm{R}$ & 0.9 & 1 & 1.0 & 1 & 0.9 & 1 \\
\hline $\mathrm{V}$ & 0.85 & 1 & 0.9 & 1 & 0.9 & 1 \\
\hline $\mathrm{K}$ & 0.9 & 1 & 0.9 & 1 & 0.9 & 1 \\
\hline
\end{tabular}

cal.: Ratio calculated from amino acid analysis.

seq.: Ratio expected from the sequence. 
E. J. Vonarx et al. CHARACTERIZATION OF INSECTICIDAL PEPTIDES FROM VENOM OF AUSTRALIAN FUNNEL-WEB SPIDERS. J. Venom. Anim. Toxins incl. Trop. Dis., 2006, 12, 2, p.225

Table 3.1: Plasma desorption mass spectrometry results.

\begin{tabular}{l|c|c}
\hline Atracotoxin ACTX- & $\begin{array}{l}\text { Mass calculated from the } \\
\text { sequence }\end{array}$ & Mass measured \\
\hline $\mathrm{Hi} 1 \mathrm{a}$ & 3929 & 3929 \\
\hline $\mathrm{Hi} 1 \mathrm{~b}$ & 4055 & 4057 \\
\hline $\mathrm{Hi} 1 \mathrm{c}$ & 4058 & 4049 \\
\hline $\mathrm{Hv} 1$ & 4050 & 4048 \\
\hline Ar1 & $*$ & $*$ \\
\hline
\end{tabular}

* Not determined.

Table 3.2: Plasma desorption mass spectrometry results of fragments from endopeptidase Glu-C cleavage of reduced and alkylated peptides.

\begin{tabular}{l|c|c}
\hline Atracotoxin ACTX- & $\begin{array}{c}\text { Mass calculated from } \\
\text { sequence }\end{array}$ & Mass measured \\
\hline Hi1a & 1092 & 1094 \\
residues 28-36 & 1092 & 1094 \\
\hline Hi1b & 1092 & $\begin{array}{c}\text { insufficient } \\
\text { signal }\end{array}$ \\
residues 29-37 & & \\
\hline Hi1c & &
\end{tabular}


E. J. Vonarx et al. CHARACTERIZATION OF INSECTICIDAL PEPTIDES FROM VENOM OF AUSTRALIAN FUNNEL-WEB SPIDERS. J. Venom. Anim. Toxins incl. Trop. Dis., 2006, 12, 2, p.226

Table 4: Effective toxic dose $\left(E D_{50}\right)$ results.

\begin{tabular}{l|c|c}
\hline Dose $(\mu \mathrm{g})$ & $\begin{array}{l}\text { \% dead or } \\
\text { writhing larvae }\end{array}$ & \% dead larvae \\
\hline 0 & 0 & 0 \\
\hline 1 & 0 & 0 \\
\hline 2 & 20 & 10 \\
\hline 3 & 20 & 10 \\
\hline 4 & 20 & 0 \\
\hline 6 & 40 & 0 \\
\hline 7.5 & 70 & 0 \\
\hline 10 & 100 & 10 \\
\hline 15 & 70 & 10 \\
\hline 20 & 90 & 60 \\
\hline 40 & 100 & 10 \\
\hline 60 & 90 & \\
\hline
\end{tabular}

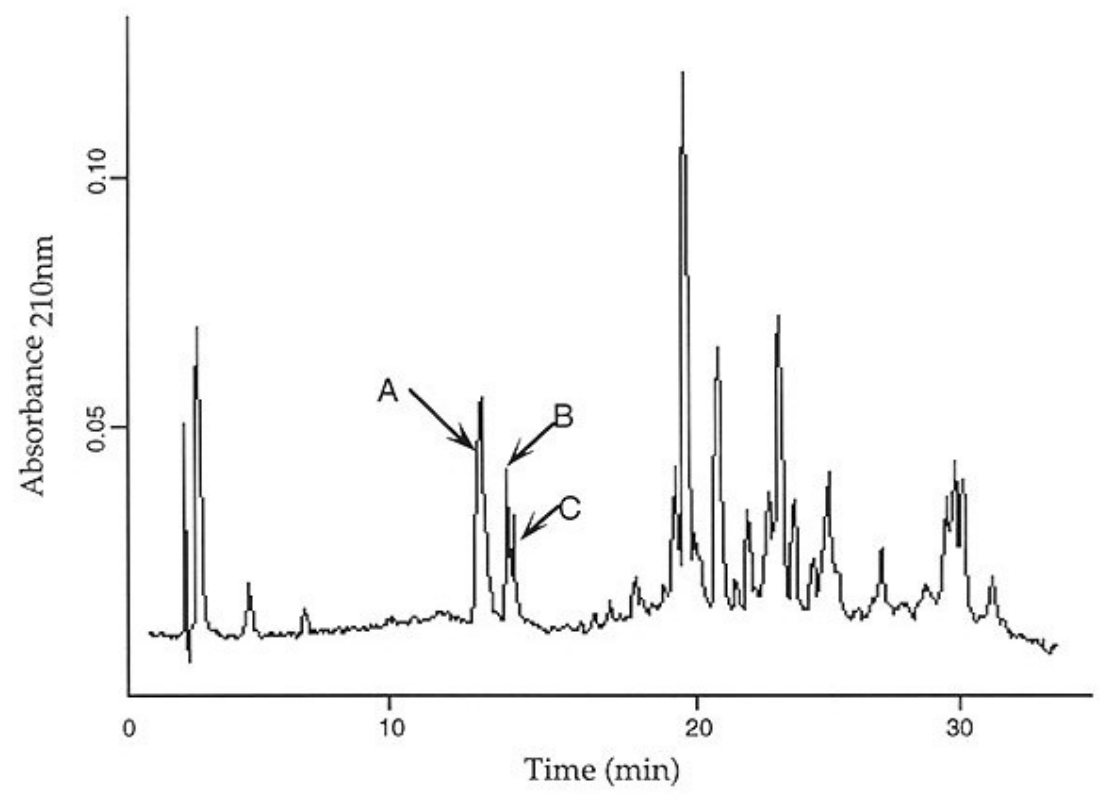

Figure 1: Reversed phase HPLC chromatogram of $H$. infensa crude venom. The peaks marked A, B and C corresponded to atracotoxins-Hi1a, b and c. 


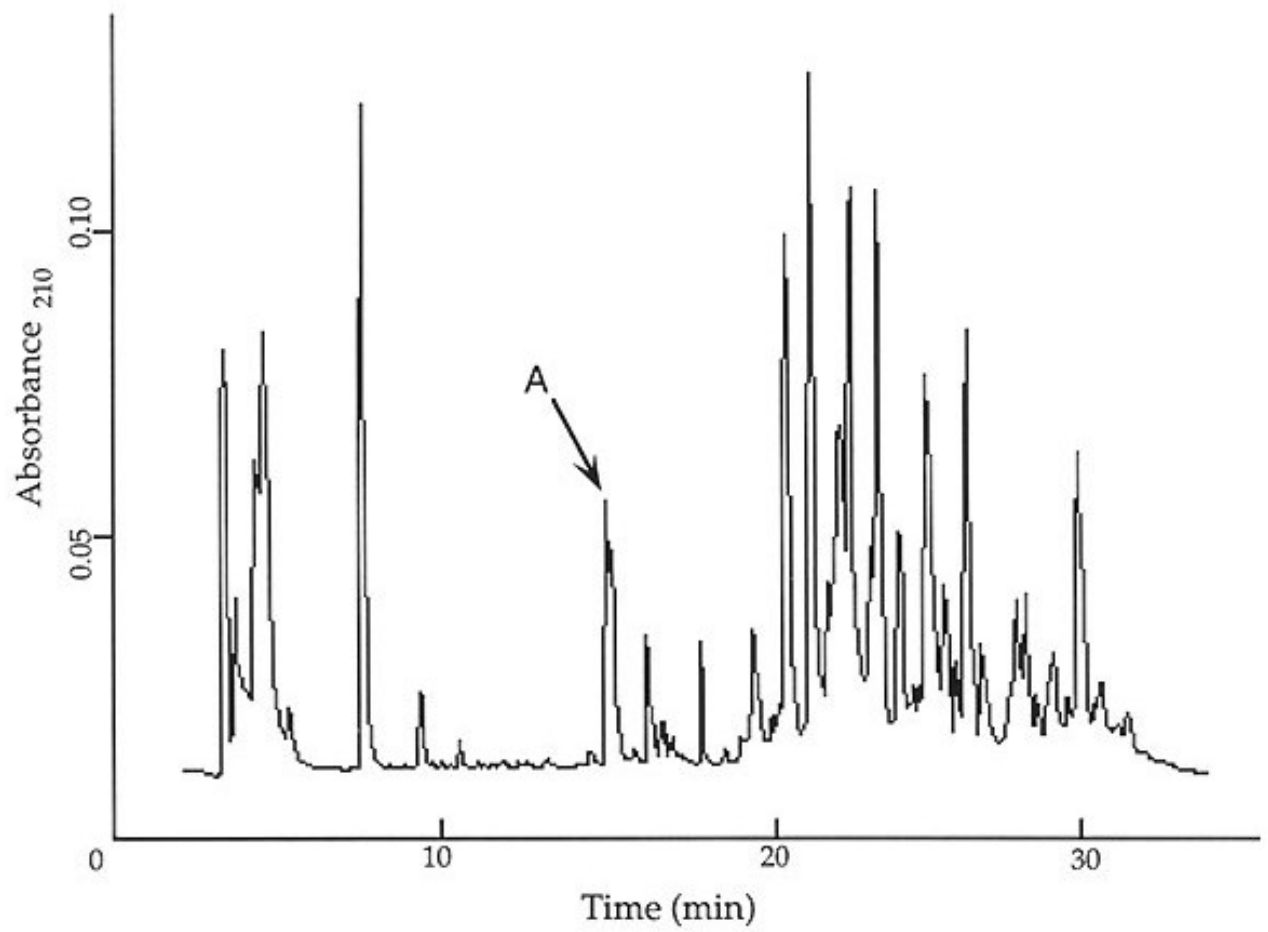

Figure 2: HPLC chromatogram of $H$. formidabilis crude venom. The HPLC gradient was as described in Materials and Methods. The peak marked A corresponded to insecticidal material. This fraction was subjected to secondary fractionation by HPLC.

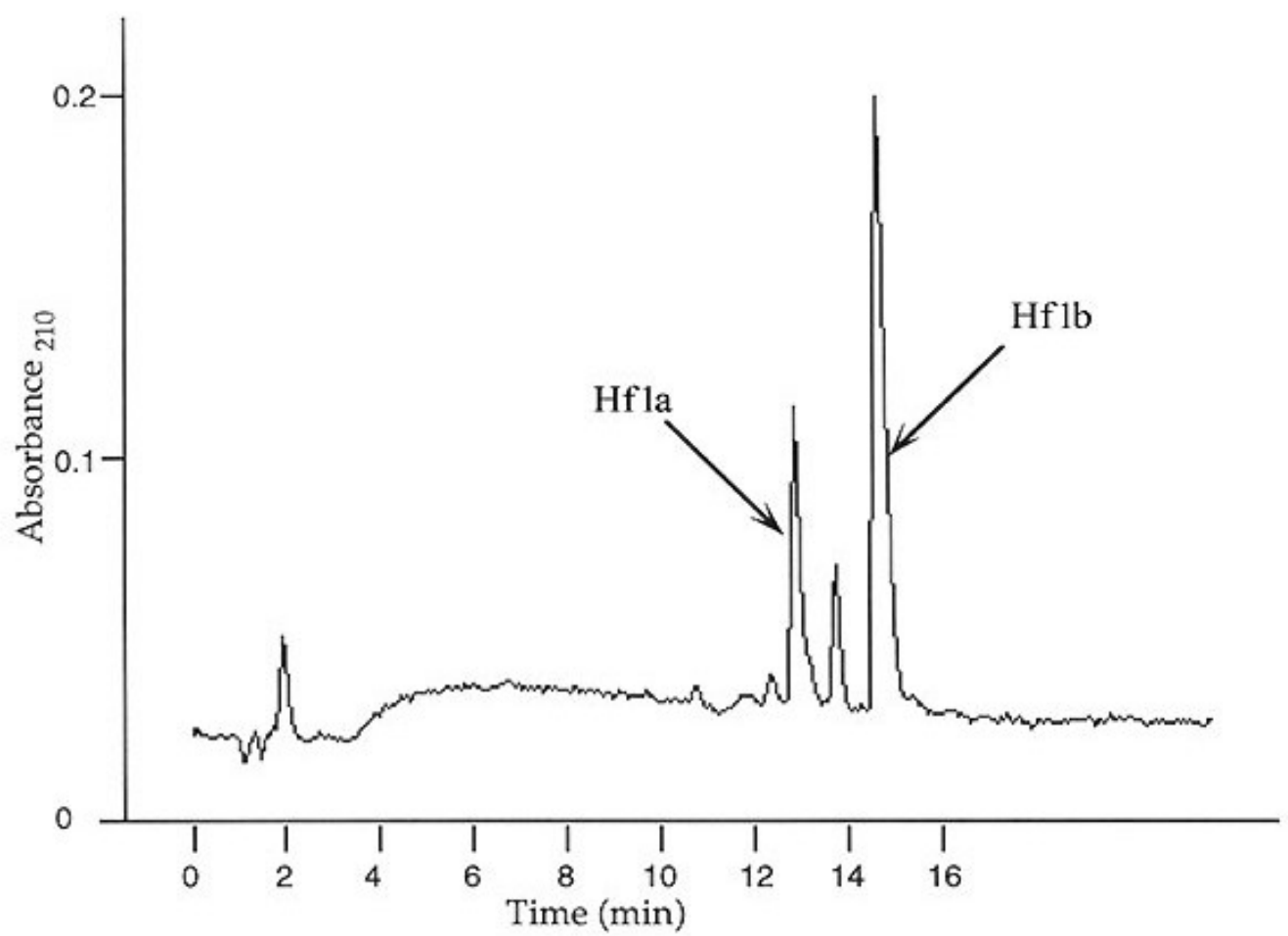

Figure 3: Secondary fractionation by HPLC of fraction A from crude $H$. formidabilis venom. Peaks corresponding to atracotoxins- $\mathrm{Hf} 1 \mathrm{a}$ and $\mathrm{b}$ are so marked. 
ACTX-Hvl $\mathrm{NH}_{2}$-SPTCIPSGQPCPYNENCCSQSCTFKENENGNTVKRCD

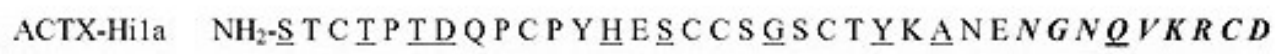

ACTX-Hilb $\mathrm{NH}_{2}$-S P TCIPIGQPCPYNENCCSQS T T K $\underline{\mathrm{T}}$ N ENGNQVKRCD-COOH

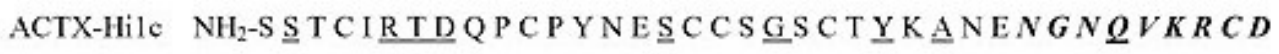

ACTX-Hfla $\mathrm{NH}_{2}$-SPTC

ACTX-Hflb $\mathrm{NH}_{2}$-SPTCI RSGQPCPYNENCCSQSCTFKT NENGNTVKRCD

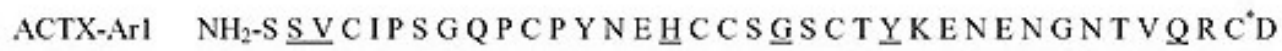

Figure 4: Atracotoxin amino acid sequences aligned, except for atracotoxin-Hf1a, as per Fletcher et al. (8). Homologies are relative to atracotoxin-Hv1. Amino acid residues in the other toxins that differ from those of atracotoxin-Hv1 are underlined. The residues in the sequences of atracotoxins-Hi1a, $b$ and $c$ shown in bold and italics were also isolated and sequenced from the endopeptidase Glu-C digests. The final cysteine residue, marked *, in the sequence of atracotoxin-Ar1 is assumed from sequence homology. The first five such residues in this toxin were identified experimentally as carboxymethyl derivatives.

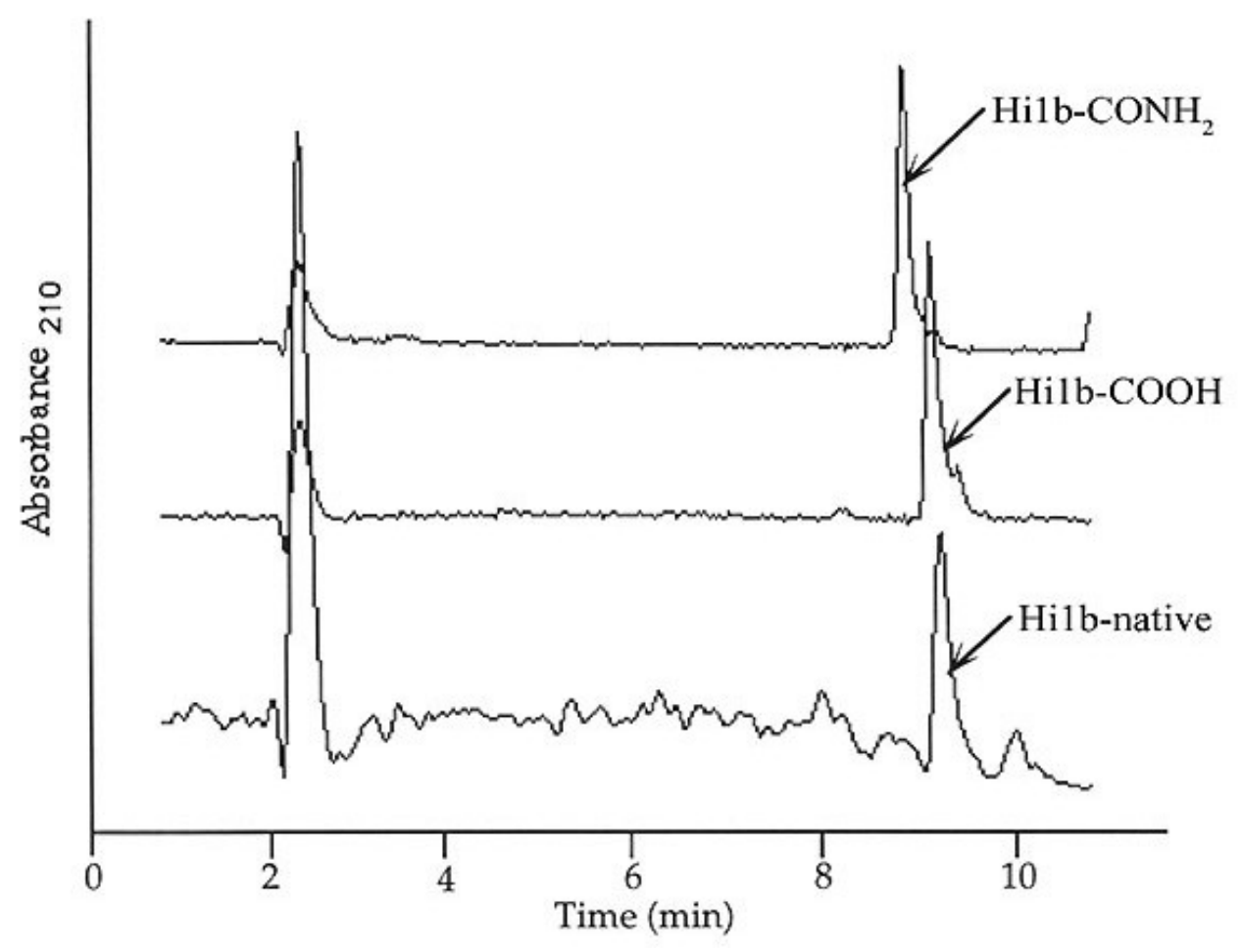

Figure 5: Comparison by reversed phase HPLC of two synthetic and one native endopeptidase Glu-C fragments of atracotoxin-Hi1b. One of the synthetic peptides is in the terminal amide form and the other has a carboxyl terminus. 


\section{DISCUSSION}

Seven toxins lethal to Helicoverpa armigera were isolated and characterized from the venom of four Australian funnel-web spiders. A feature of these toxins is the considerable homology between them, particularly in the regions of the carboxyl termini and in the placement of the cysteine residues. From this, we may postulate that disulfide bridge arrangements will be similar in all of these toxins and of great importance to bioactivity, since no toxic effect was observed when reduced and alkylated atracotoxin-Hi1a was subjected to the standard bioassay procedure. All cysteine residues seem to be involved in disulfide bridging, since no free cysteines were detected in the toxins by alkylation and gas-phase sequencing of the toxins without prior reduction.

Third instar Helicoverpa armigera larvae were not affected by oral ingestion of crude $H$. infensa venom. Constituent toxins are also likely to be inactive on ingestion by the larvae.

Although presenting related activity, the toxins that we characterized showed limited structural similarity to previously reported insect-active toxins from spider venoms. For example, toxins isolated from the venom of the spider Plectreurys tristis (14) present relative molecular mass $\left(\mathrm{M}_{\mathrm{r}}\right)$ of approximately 5000 , higher than the $\mathrm{M}_{\mathrm{r}}$ near 4000 of the toxins in this study. $E D_{50}$ values for $P$. tristis toxins in a bioassay based on Helicoverpa viriscens ranged from 0.21 to greater than $10 \mu \mathrm{g} / \mathrm{g}$.

Toxins isolated from the venom of the spider Hololena curta $(13,21)$ are peptides of 36 or 38 amino acids with four disulfide bonds. These toxins have amidated carboxy termini and produced irreversible paralysis in the cricket Acheta domestica at $\mathrm{LD}_{50}$ values form $4-20 \mu \mathrm{g} / \mathrm{g}$. These curtatoxins were reported to cause a flaccid paralysis consistent with a presynaptic blockage of the insect neuromuscular junction.

The $\mu$-agatoxins from Agelenopsis aperta spider venom (18) are closer in structure to our toxins. They are single-chain toxins of approximate $M_{r}$ of 4200 . The disulfide bridging is different, however, in that the $\mu$-agatoxins have four disulfide bridges, whereas most of our toxins have only three such bridges. The $\omega$-agatoxins (1) have $M_{r}$ 's in the range of 7500-11000 and are neuronal calcium channel blockers. There is little sequence homology between our toxins and the $\mu$ - and $\omega$-agatoxins. Lethal doses for the $\mu$-agatoxins in Helicoverpa viriscens ranged from $16-100 \mu \mathrm{g} / \mathrm{g}$. Four $\mu$ agatoxins were reported to be amidated at their carboxyl termini. 
Figueiredo et al. (6) reported the characterization of an insect-active peptide toxin from the venom of the spider Phoneutria nigriventer. This toxin had $\mathrm{M}_{\mathrm{r}}$ of 5242 and 10 cysteine residues. Its $L D_{50}$ was found to be $0.02 \mu \mathrm{g} / \mathrm{g}$ in houseflies and in the range of $0.5-2.5 \mu \mathrm{g} / \mathrm{g}$ in cockroaches. Surprisingly, this toxin showed marked selectivity in toxicity among insect species.

Six insecticidal peptides were isolated from the venom of Aptostichus schlingeri (19). These toxins had either 6 or 8 cysteine residues and carboxyl termini in the free acid form. Their $\mathrm{ED}_{50}$ values in Manduca sexta insects ranged from 0.1 to more than $5 \mu \mathrm{g} / \mathrm{g}$. In Spodoptera exigua insects, these toxins displayed ED ${ }_{50}$ 's from $0.5-1.0 \mu \mathrm{g} / \mathrm{g}$. The toxins from the venoms of Australian funnel-web spiders have $E D_{50}$ levels comparable to those of previously reported toxins, although they were measured in different target insects.

A seemingly common sequence motif shared by almost all of the above-mentioned toxins involves three cysteine residues, consistently arranged in the pattern of a single cysteine followed by either 6,7 or 8 other amino acids, followed in turn by two consecutive cysteine residues. In the funnel-web spider toxins, this grouping occurred between amino acids 11 and 17 (see Figure 4). Conservation of this pattern among many insect-active toxins may indicate some functional importance. Atracotoxin- $\mathrm{Hf} 1 \mathrm{a}$ is unusual in that it does not show this arrangement. It has two pairs of cysteine residues beginning at positions 14 and $17-a$ total of 8 rather than 6 cysteine residues. Could this mean that atracotoxin-Hf1a has a mode of action in insects different to that of the other atracotoxins?

The atracotoxins described here are a homologous group quite distinct from the toxins active against primates previously isolated from the venoms of Australian funnel-web spiders $(3,17)$. Consequently, no activity was expected or found for atracotoxin-Hv1 when a solution of it was subcutaneously injected into newborn mice. Subsequent work involving chemical synthesis of these toxins and of their analogues, as well as secondary structure determination, has been carried out and forms the basis of a report by Fletcher et al. (8).

\section{ACKNOWLEDGEMENTS}

The authors thank the Rural Industries Research and Development Corporation of Australia, the Rural Credits Development Fund of Australia, Deakin Research Ltd, and Deakin University for supporting this work. They are also indebted to Dr. M. Gray 
for identification of spiders, to Dr. M. Kochersburger of Applied Biosystems Industries for mass spectral analysis, and to Mrs. L. Wright for technical assistance.

\section{REFERENCES}

1 ADAMS ME., BINDOKAS VP., HASEGAWA L., VENEMA VJ. Omega-agatoxins: novel calcium channel antagonists of two subtypes from funnel web spider (Agelenopsis aperta) venom. J. Biol. Chem., 1990, 265, 861-7.

2 ATKINSON RK., VONARX EJ., HOWDEN MEH. Effects of whole venom and venom fractions from several Australian spiders, including Atrax (Hadronyche) species, when injected into insects. Comp. Biochem. Physiol., 1996, 114C, 113-7.

3 BROWN MR., SHEUMACK DD., TYLER MI., HOWDEN ME. Amino acid sequence of versutoxin, a lethal neurotoxin from the venom of the funnel-web spider Atrax versutus. Biochem. J., 1988, 250, 401-5.

4 EITAN M., FOWLER E., HERRMANN R., DUVAL A., PELHATE M., ZLOTKIN E. A scorpion venom neurotoxin paralytic to insects that affects sodium current inactivation: purification, primary structure, and mode of action. Biochemistry, 1990, 29, 5941-7.

5 ENTWISTLE ID., JOHNSTONE RA., MEDZIHRADSZKY D., MAY TE. Isolation of a pure toxic polypeptide from the venom of the spider Phoneutria nigriventer and its neurophysiological activity on an insect femur preparation. Toxicon, 1982, 20, 1059-67.

6 FIGUEIREDO SG., GARCIA ME., VALENTIM AC., CORDEIRO MN., DINIZ CR., RICHARDSON M. Purification and amino acid sequence of the insecticidal neurotoxin Tx4(6-1) from the venom of the 'armed' spider Phoneutria nigriventer (Keys). Toxicon, 1995, 33, 83-93.

7 FINNEY DJ. Probit analysis. 3.ed. Cambridge: Cambridge University Press, 1971. 333p.

8 FLETCHER Jl., SMITH R., O'DONOGHUE SI., NILGES M., CONNOR M., HOWDEN ME., CHRISTIE MJ., KING GF. The structure of a novel insecticidal neurotoxin, omega-atracotoxin-HV1, from the venom of an Australian funnel web spider. Nat. Struct. Biol., 1997, 4, 559-66. 
9 HAMMOCK BD., McCUTCHEN BF., BEETHAM J., CHOUDARY PV., FOWLER E., ICHINOSE R., WARD VK., VICKERS JM., BONNING BC., HARSHMAN LG., GRANT D., UEMATSU T., LANZREIN B., MAEDA S. Development of recombinant viral insecticides by expression of an insect-specific toxin and insect-specific enzyme in nuclear polyhedrosis viruses. Arch. Insect Biochem. Physiol., 1993, 22, 315-44.

10 HOUMARD J., DRAPEAU GR. Staphylococcal protease: a proteolytic enzyme specific for glutamoyl bonds. Proc. Nat. Acad. Sci. U.S.A., 1972, 69, 3506-9.

11 JOHNSON JH., BLOOMQUIST JR., KRAPCHO KJ., KRAL RM. Jr., TROVATO R., EPPLER KG., MORGAN TK., DELMAR EG. Novel insecticide peptides from Tegenaria agrestis spider venom may have a direct effect on the insect central nervous system. Arch. Insect Biochem. Physiol., 1998, 38, 19-31.

12 KING GF., TEDFORD HW., MAGGIO F. Structure and function of insecticidal neurotoxins from Australian funnel-web spiders. J. Toxicol. Toxin Rev., 2002, 21, 359-89.

13 QUISTAD GB., REUTER CC., SKINNER WS., DENNIS PA., SUWANRUMPHA S., FU EW. Paralytic and insecticidal toxins from the funnel web spider, Hololena curta. Toxicon, 1991, 29, 329-36.

14 QUISTAD GB., SKINNER WS. Isolation and sequencing of insecticidal peptides from the primitive hunting spider, Plectreurys tristis (Simon). J. Biol. Chem., 1994, 269, 11098-101.

15 QUISTAD GB., SUWANRUMPHA S., JAREMA MA., SHAPIRO MJ., SKINNER WS., JAMIESON GC., LUI A., FU EW. Structures of paralytic acylpolyamines from the spider Agelenopsis aperta. Biochem. Biophys. Res. Commun., 1990, 169, 51-6.

16 SCHMIDT JO. Chemistry, pharmacology, and chemical ecology of ant venoms. In: PIEK T. Ed. Venoms of the hymenoptera: biochemical, pharmacological and behavioural aspects. London: Academic Press, 1986: 425-509.

17 SHEUMACK DD., CLAASSENS R., WHITELEY NM., HOWDEN ME. Complete amino acid sequence of a new type of lethal neurotoxin from the venom of the funnel-web spider Atrax robustus. FEBS Lett., 1985, 181, 154-6. 
18 SKINNER WS., ADAMS ME., QUISTAD GB., KATOAKA H., CESARIN BJ., ENDERLIN FE., SCHOOLEY DA. Purification and characterization of two classes of neurotoxins from the funnel web spider, Agelenopsis aperta. J. Biol. Chem., 1989, 264, 2150-5.

19 SKINNER WS., DENNIS PA., LI JP., QUISTAD GB. Identification of insecticidal peptides from venom of the trap-door spider, Aptostichus schlingeri (Ctenizidae). Toxicon, 1992, 30, 1043-50.

20 SKINNER WS., DENNIS PA., LUI A., CARNEY RL., QUISTAD GB. Chemical characterization of acylpolyamine toxins from the venom of a trap-door spider and two tarantulas. Toxicon, 1990, 28, 541-6.

21 STAPLETON A., BLANKENSHIP DT., ACKERMANN BL., CHEN TM., GORDER GW., MANLEY GD., PALFREYMAN MG., COUTANT JE., CARDIN AD. Curtatoxins: neurotoxic insecticidal polypeptides isolated from the funnel-web spider Hololena curta. J. Biol. Chem., 1990, 265, 2054-9.

22 SUTHERLAND SK. Antivenom to the venom of the male Sydney funnel-web spider Atrax robustus: preliminary report. Med. J. Aust., 1980, 2, 437-41.

23 ZILBERBERG N., ZLOTKIN E., GUREVITZ M. The cDNA sequence of a depressant insect selective neurotoxin from the scorpion Buthotus judaicus. Toxicon, 1991, 29, 1155-8.

24 ZLOTKIN E., EITAN M., PELHATE M., CHEJANOVSKY N., GUREVITZ M., GORDON D. Insect specific neurotoxins from scorpion venom that affect sodium current inactivation. J. Toxicol. Toxin Rev., 1994, 13, 25-43. 